\title{
THE ASSOCIATION OF DIABETES DURATION WITH THE SEVERITY OF DIABETIC RETINOPATHY
}

\author{
Intan Lamy Manao ${ }^{1 *}$, Hesti Triwahyu Hutami ${ }^{2}$, Fifin Luthfia Rahmi ${ }^{2}$, Arnila Novitasari Saubig ${ }^{2}$ \\ ${ }^{1}$ Undergraduate Program, Faculty of Medicine, Diponegoro University, Semarang, Indonesia \\ ${ }^{2}$ Department of Ophtalmology, Faculty of Medicine, Diponegoro University, Semarang, Indonesia \\ *Corresponding author, E-mail: intan.manao@gmail.com
}

\begin{abstract}
Background: The prevalence of diabetic patients is increasing over the years. It will increase the incidence of microvascular complications due to prolonged hyperglycemia in diabetic patient. Diabetic retinopathy is one of microvascular complication which is one of the leading causes of blindness in the world. Prolonged hyperglycemia in diabetic patient cause toxicity to the retina which cause nerve and vascular damage and death to the retina. In this study was analyzed the association of diabetes duration with the severity of diabetic retinopathy associated with many cases of delay in diagnosing diabetes recently. Objective: This study aims to investigate the association of diabetes duration with the severity of diabetic retinopathy. Methods: A crosssectional design was performed by collecting data from the medical records of diabetic patients who were diagnosed with diabetic retinopathy in Diponegoro National Hospital in July-December 2019 using purposive sampling method. Research subjects were 51 patients who fulfilled the inclusion and exclusion criteria. The data were analyzed using non-parametric Chi Square test with $\mathrm{p}<0.05$ was considered statistically significant. Results: Prevalence was more in the age group of 51-60 years $(45,1 \%)$, female $(58,8 \%)$, diabetics <5 years $(41,2 \%)$, and PDR $(72,6 \%)$. Chi Square analysis shows no statistically significant association between duration of diabetes with the severity of diabetic retinopathy $(\mathrm{p}=0,881)$. Conclusion: There was no statistically significant association between duration of diabetes with the severity of diabetic retinopathy
\end{abstract}

Keywords: Diabetes mellitus, duration of diabetes, the severity of diabetic retinopathy

\section{INTRODUCTION}

Diabetes mellitus is one of the major health problems for people in the world. ${ }^{1}$ According to the International Diabetes Federation (IDF), the number of people with diabetes is increasing every year. The number of people suffering from diabetes in 2019 increased to 487.3 million people compared to 2018 which was 451 million people. Indonesia is in the 7th position of the top 10 countries in the world with 10.7 million people with diabetes aged 20-79 years. The number of people with diabetes is expected to increase to 612.5 million in 2030 and 762.3 million in $2045 .^{2}$

The microvascular complication of diabetes mellitus which is one of the leading causes of blindness in the world, especially in the working age group is diabetic retinopathy., The data from the Ministry of Health of the Republic of Indonesia showed that the prevalence of diabetic retinopathy in Indonesia in 2018 was $42.6 \%$ or around 24,600 people. Meanwhile in 2030, the prevalence is estimated to increase to 98,400 people. ${ }^{5}$

Piyus et al. reported that long-term diabetes was more likely to develop diabetic retinopathy. In their study, prevalence of diabetic retinopathy was $9.44 \%$ in people who had diabetes less than 5 years, while the prevalence increased to $76.47 \%$ for a period of 20-25 years. ${ }^{6}$ Furthermore, the research of Fath et al. showed a significant relationship between the severity of diabetic retinopathy and the duration of diabetes. The severity of diabetic retinopathy will increase if a person has diabetes for a long time. In their study, the prevalence of Non-Proliferative Diabetic Retinopathy (NPDR) was $63.6 \%$ and Proliferative Diabetic Retinopathy (PDR) was $4.15 \%$ in people who had diabetes less than 20 years. Whereas for a duration of more than 40 years, the prevalence of NPDR was $12.5 \%$ and PDR was $87.5 \%{ }^{7}$

Both of the above occurred due to the chronic hyperglycemia condition in people with diabetic retinopathy, where the longer they suffer from diabetes shows the longer the toxicity condition to the retina, which cause nerve and vascular death to the retina. ${ }^{8,9}$ Diabetic retinopathy that may occur and will worsen in people with long-term diabetes could increase the risk of blindness. The result of previous studies did show a relationship between diabetes 
duration with diabetic retinopathy. ${ }^{6,7}$ However, there are many cases that show delay in diagnosing diabetes recently. The delay in diagnosing diabetes causes the patient to develop complications of diabetes, such as retinopathy. ${ }^{10,11}$ Because there is no current study in Indonesia regarding the diabetes duration with diabetic retinopathy associated with many cases of delay in diagnosing diabetes recently, this study aims to prove whether there is an association between the diabetes duration with the severity of diabetic retinopathy in regards to many cases of delay in diagnosing diabetes.

\section{METHODS}

This study was an analytic observational study with a cross sectional study design using secondary data from medical record. This study was conducted at the medical record installation of Diponegoro National Hospital. This study used a purposive sampling technique in which the selection of subjects was in accordance with the research objectives and fulfilled the inclusion and exclusion criteria. The inclusion criteria in this study was all medical record data of diabetic retinopathy patients who were treated at Diponegoro National Hospital in the period of July-December 2019. The exclusion criteria in this study were patients with hypertension, glaucoma, cataract, other posterior segment disorders, history of intraocular surgery and laser, and patient medical records that do not contain data of diabetes duration and diagnosis of the severity of diabetic retinopathy.

Ethical clearance has been received from KEPK with number 181/EC/KEPK/FKUNDIP/VII/2020 and Diponegoro National Hospital with number 1920/UN7.9/PP/2020. Processing, analysis, and presentation of data were done using computer software. Furthermore, to determine the association between the 2 variables, the data were analyzed using the non-parametric Chi Square test with a significance of $\mathrm{p}<0.05$.

\section{RESULT}

This research was carried out in the medical record installation of Diponegoro National Hospital in September 2020. The data of the research subjects that obtained in this study were the medical records of 51 patients consisting of 7 patients with NPDR, 7 patients with severe NPDR and 37 patients with PDR. Implementation of data collection for research subjects shown in the diagram of the consolidated standards of reporting trials (consort) in Figure 1.

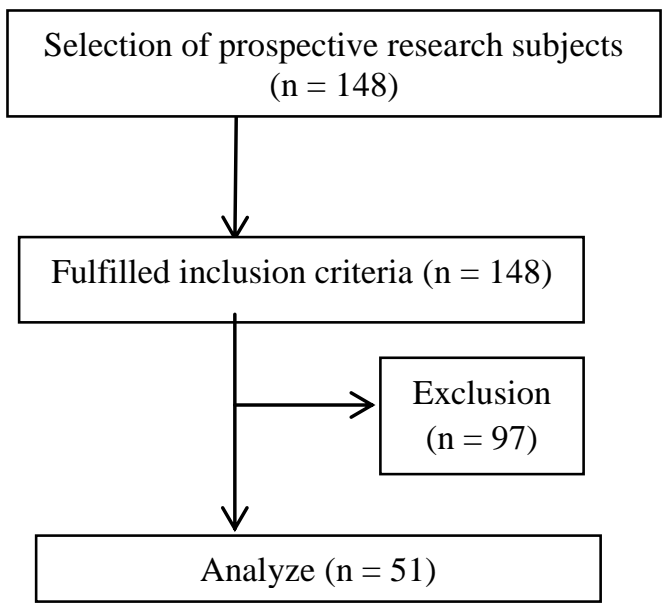

Figure 1. Consort Diagram

The characteristics of the subjects in this study shown in table 1. In this study, the subjects were dominated by the age group of 5160 years $(45.1 \%)$ and female $(58.8 \%)$. The highest distribution of the duration of diabetes among the subjects in this study was <5 years $(41.2 \%)$. In this study, the highest distribution of the severity of diabetic retinopathy was PDR $(72.6 \%)$.

Table 1. The Characteristics of subjects

\begin{tabular}{lcc}
\hline \multicolumn{1}{c}{ Variable } & F & \% \\
\hline Age & & \\
31-40 years & 2 & 3,9 \\
41-50 years & 20 & 39,2 \\
51-60 years & 23 & 45,1 \\
61-70 years & 5 & 9,8 \\
71-80 years & 1 & 2 \\
\hline Gender & & \\
Male & 21 & 41,2 \\
Female & 30 & 58,8 \\
\hline Duration of Diabetes & & \\
< 5 years & 21 & 41,2 \\
5-10 years & 13 & 25,5 \\
> 10 years & 17 & 33,3 \\
\hline Severity of Diabetic Retinopathy & & \\
Mild NPDR & 0 & 0 \\
Moderate NPDR & 7 & 13,7 \\
Severe NPDR & 7 & 13,7 \\
PDR & 37 & 72,6 \\
\hline
\end{tabular}


The results of the study regarding the association of duration of diabetes with the severity of diabetic shown in table 2 . The results showed that the value of $p=0.881(p>0.05)$. Therefore, this study shows that there is no significant association between duration of diabetes to the severity of diabetic retinopathy.

Table 2. The association of diabetes duration with the severity of diabetic retinopathy

\begin{tabular}{cccccccc}
\hline $\begin{array}{c}\text { Duration } \\
\text { of }\end{array}$ & \multicolumn{2}{c}{$\begin{array}{c}\text { Moderate } \\
\text { NPDR }\end{array}$} & \multicolumn{2}{c}{$\begin{array}{c}\text { Severe } \\
\text { NPDR }\end{array}$} & \multicolumn{2}{c}{ PDR } & $\boldsymbol{p}$ \\
\cline { 2 - 8 } Diabetes & $\mathbf{n}$ & $\boldsymbol{\%}$ & $\mathbf{n}$ & $\boldsymbol{\%}$ & $\mathbf{n}$ & $\mathbf{\%}$ & \\
\hline 5 years & 5 & 9,8 & 1 & 2 & 15 & 29,4 & $0,881^{\ddagger}$ \\
5-10 years & 2 & 3,9 & 2 & 3,9 & 9 & 17,6 & \\
$>10$ years & 0 & 0 & 4 & 7,8 & 13 & 25,5 & \\
Total & 7 & 13,7 & 7 & 13,7 & 37 & 72,5 & \\
\hline Notes: * Significant $(p<0,05) ;{ }^{\ddagger}$ Chi Square Test
\end{tabular}

\section{DISCUSSION}

In this study, the subjects were dominated by the age group of 51-60 years. This is in accordance with Riskesdas data in 2018 which revealed the highest prevalence of diabetic patients is in the age group of 55-64 year. ${ }^{12}$ The result of this study is also consistent with the previous research by Kiran et al. who got the prevalence of diabetic retinopathy increases with patient age ( $>50$ years). This may be due to the body's aging process causes disruption of glucose homeostasis and metabolism. ${ }^{13,14}$

In this study, the most diabetic retinopathy patients were female patients. This is in accordance with Riskesdas data in 2018 which revealed that diabetic patient in Indonesia were more likely to be female than male. ${ }^{12}$ Furthermore, the result of this study is consistent with the previous research by Fernanda et al., in which the average of $\mathrm{HbAlc}$ value in female was higher than male. This is due to poor blood sugar control in female patient which is associated with socio-economic factors, such as low education, income, and awareness in maintaining personal health. ${ }^{15}$ The result of this study is also consistent with the study done by Mei Li et al., who got the prevalence of PDR over the age of 60 were mostly women $(31.1 \%)$. This is due to hormonal factor, such as estrogen levels which decreases in women over 60 years of age. ${ }^{16}$ Therefore, based on the research by Kyung et al., estrogen hormone therapy is very useful, especially in preventing the progression of diabetic retinopathy in postmenopausal women. ${ }^{17}$

The highest distribution of diabetic retinopathy severity in this study was PDR $(72.6 \%)$. The result is different from the study done by Fath et al. and Razia et al. who got mild NPDR. ${ }^{7,18}$ It is not yet known what factors cause the prevalence of PDR more than NPDR. Therefore, further research is needed in order to prove what factors cause the prevalence of PDR more than NPDR. ${ }^{19}$ The highest distribution of duration of diabetes in this study was $<5$ years. The result of this study is different from previous research by Razia et al. who got $>15$ years. ${ }^{18}$

Based on Chi Square test, this study shows that there is no significant association between duration of diabetes and the severity of diabetic retinopathy $(p=0.881)$. The result is different from the study done by Abhishek et al. and Fath et al. which showed a significant relationship between duration of diabetes and the severity of diabetic retinopathy. ${ }^{7,20}$ The result of this study statistically indicates that there is no association between diabetes duration with the severity of diabetic retinopathy. However, in this study, when viewed from a clinical point of view, the study subjects who had diabetes $>10$ years had more PDR $(25.5 \%)$ compared to moderate NPDR and severe NPDR. The result of this study is consistent with the research by Fath et al. who got more prevalence of PDR than moderate and severe NPDR with longer duration of diabetes. ${ }^{7}$

The difference between the result of this study and the previous study statistically was probably due to the fact that many study subjects had diabetes $\leq 5$ years but had been diagnosed with PDR. This is due to delay in diagnosing diabetes for the first time. The delay in diagnosing diabetes causes the patient to develop complications of diabetes, such as retinopathy, nephropathy, and gangrene..$^{10}$ In the study done by Dipika et al., $18.04 \%$ of patients diagnosed with diabetes at $\leq 6$ months had experienced at least one diabetes microvascular complication, and diabetic retinopathy was the most common. ${ }^{11}$ Delay in diagnosing diabetes is also due to diabetes is asymptomatic. Another possible factors that contributed to undiagnosed 
diabetes case are due to the patient's low knowledge about diabetes and low awareness for checking health earlier. ${ }^{10}$

Another possibility that causes no statistically significant association between diabetes duration with the severity of diabetic retinopathy in this study is the presence of other risk factors associated with the incidence of diabetic retinopathy. Another risk factors that significantly associated with the incidence of diabetic retinopathy include poor blood sugar control $(\mathrm{HbA} 1 \mathrm{c}>7 \%)$, the presence of other microvascular complications (nephropathy), and smoking. ${ }^{21,22}$ The study done by Abhishek et al. revealed that other risk factors that contributed to increase the severity of diabetic retinopathy were the use of insulin, total cholesterol levels, serum creatinine, and macroalbuminuria. ${ }^{20}$ The absence of an assessment of these risk factors in this study causes no statistically significant association between duration of diabetes to the severity of diabetic retinopathy.

\section{CONCLUSION AND SUGGESTIONS}

The result of this study statistically indicates that there is no association between duration of diabetes with the severity of diabetic retinopathy. This study has limitations because it only used secondary data from existing patient medical records. Therefore, the opportunity to meet the research subjects in order to explore other risk factors and necessary information was limited. In future studies, it is suggested that data collection will not only using secondary data from the patient's medical records. But also meeting research subjects directly so that exploring risk factors and necessary information could be done completely.

\section{REFERENCES}

1. Al-Lawati JA. Diabetes Mellitus: A Local and Global Public Health Emergency! Oman Medical Journal. 2017;32(3):177179.

2. International Diabetes Federation. IDF Diabetes Atlas 9th edn. DF Diabetes Atlas, 9th edn. Brussels, Belgium: IDF; 2019. Available at: https://www.diabetesatlas.org

3. Cheloni R, Gandolfi SA, Signorelli C, Odone A. Global prevalence of diabetic retinopathy: Protocol for a systematic review and meta-analysis. BMJ Open. 2019;9(3):1-5.

4. Flaxman SR, Bourne RRA, Resnikoff S, Ackland P, Braithwaite T, Cicinelli M V., et al. Global causes of blindness and distance vision impairment 1990-2020: a systematic review and meta-analysis. Lancet Global Health. 2017;5(12):12211234.

5. Kartasasmita AS. Retinopati Diabetik: Pergeseran Paradigma Kebutaan Pada Era Milenial [Internet]. 2018. [updated 2018 Nov 12; cited 2020 Feb 2]. Available from:

http://www.yankes.kemkes.go.id/readretinopati-diabetik-pergeseran-paradigmakebutaan-pada-era-milenial-5984.html

6. Gupta R, Kotecha M, Bansal P. Frequency of diabetic retinopathy in patients with diabetes mellitus and its correlation with duration of diabetes mellitus. Medical Journal Dr. D.Y. Patil University. 2013;6(4):366-369.

7. El-Bab MF, Shawky N, Al-Sisi A, Akhtar M. Retinopathy and risk factors in diabetic patients from Al-Madinah AlMunawarah in the Kingdom of Saudi Arabia. Clinical Ophthalmology. 2012;6(1):269-276.

8. Liu Y, Yang J, Tao L, Lv H, Jiang X, Zhang $\mathrm{M}$, et al. Risk factors of diabetic retinopathy and sight-threatening diabetic retinopathy: A cross-sectional study of 13 473 patients with type 2 diabetes mellitus in mainland China. BMJ Open. 2017;7(9):1-11.

9. Tah V, Mall S, Myerscough J, Saha K, Emsley E, Swampillai A, et al. Diabetic Retinopathy - An Update on Pathophysiology, Classification, Investigation and Treatment. IntechOpen. 2014;6(2):249-285.

10. Subramaniam K. Faktor-Faktor yang Mempengaruhi Keterlambatan Diagnosis Diabetes Melitus Tipe 2 di Wilayah Kerja Puskesmas Abang I, Kabupaten Karangasem Bali Tahun 2015. Intisari Sains Medis. 2016;6(1):83-91.

11. Bansal D, Gudala K, Esam HP, Nayakallu $\mathrm{R}$, Vyamusani RV, Bhansali A. 
Microvascular Complications and Their Associated Risk Factors in Newly Diagnosed Type 2 Diabetes Mellitus Patients. International Journal of Chronic Diseases. 2017;11(2):1-7.

12. Tim Riskesdas 2018. Laporan Nasional Riset Kesehatan Dasar 2018. Lembaga Penerbit Badan Penelitian dan Pengembangan Kesehatan Kementerian Kesehatan Republik Indonesia; 2019.

13. Shah K, Gandhi A, Natarajan S. Diabetic Retinopathy Awareness and Associations with Multiple Comorbidities: Insights from DIAMOND Study. Indian Journal of Endocrinology and Metabolism. 2018;22(1):30-35.

14. Katarzyna M, Godziejewska-Zawada M. Diabetes in the elderly. Japanese Journal of Geriatrics. 2017;47(5):415-418.

15. Duarte FG, Da Silva Moreira S, Almeida MDCC, De Souza Teles CA, Andrade CS, Reingold AL, et al. Sex differences and correlates of poor glycaemic control in type 2 diabetes: A cross-sectional study in Brazil and Venezuela. BMJ Open. 2019;9(3):1-8.

16. Li M, Wang Y, Liu Z, Tang X, Mu P, Tan $\mathrm{Y}$, et al. Females with Type 2 Diabetes Mellitus Are Prone to Diabetic Retinopathy: A Twelve-Province CrossSectional Study in China. Journal of Diabetes Research Hindawi. 2020;5(1):19.

17. Na KS, Jee DH, Han K, Park YG, Kim MS, Kim EC. The ocular benefits of estrogen replacement therapy: A population-based study in postmenopausal korean women. PLoS One. 2014;9(9):1-6.

18. Ahmed R, Khalil S, Al-Qahtani M. Diabetic retinopathy and the associated risk factors in diabetes type 2 patients in Abha, Saudi Arabia. Journal of Family and Community Medicine. 2016;23(1):18-24.

19. Manullang YR, Rares L, Sumual V. Prevalensi Retinopati Diabetik Pada Penderita Diabetes Melitus Di Balai Kesehatan Mata Masyarakat (Bkmm) Propinsi Sulawesi Utara Periode Januari Juli 2014. Jurnal e-CliniC. 2016;4(1):1-6.
20. Padha A, Sharma S, Gupta D, Koul P. Diabetes mellitus longer than 10 years - a study from a tertiary care hospital. Journal of Medical Science Clinical Research. 2018;06(11):336-344.

21. Lima VC, Cavalieri GC, Lima MC, Nazario NO, Lima GC. Risk factors for diabetic retinopathy: A case-control study. International Journal of Retina and Vitreous. 2016;2(1):1-7.

22. Ayoor AK, Kotancheri R, Babu A, K S. Study of Association of Diabetic Retinopathy With Dyslipidaemia in Type 2 Diabetes Mellitus Patients. Indian Journal of Clinical Experimental Ophthalmology. 2017;4(78):436-439. 